DOi: $10.5578 /$ fmbd.66856

\title{
Analytical Evaluation of Second Virial Coefficient Using Sutherland Potential and Its Application to Real Gases
}

\author{
Elif Somuncu \\ Department of Physics, Faculty of Arts and Sciences, Giresun University, Giresun, Turkey \\ Email: elf_smnc@hotmail.com
}

Geliş Tarihi:14.12.2016 ～； Kabul Tarihi:19.04.2018

\begin{tabular}{|c|c|}
\hline & Abstract \\
\hline $\begin{array}{c}\text { Keywords } \\
\text { Second virial } \\
\text { coefficient; Sutherland } \\
\text { potential; } \\
\text { Thermodynamics }\end{array}$ & $\begin{array}{l}\text { A simple and efficient analytical formula for the calculation of second virial coefficient over Sutherland } \\
\text { potential is derived. The compute conclusions of the second virial coefficient determined for } \\
\text { Sutherland potential are compared with calculations of second virial coefficient using Lennard-Jones } \\
(12-6) \text { potential and Exp- } 6 \text { potential. The accuracy of the analytical formula is tested by application to } \\
\text { molecules } K r, X e, N e \text { and } A r \text {. The results of the calculations for wide temperature range show } \\
\text { excellent agreement with the data existing in the literature. }\end{array}$ \\
\hline
\end{tabular}

\section{Sutherland Potansiyeli Kullanılarak İkinci Virial Katsayısının Analitik Belirlenmesi ve Gerçek Gazlara Uygulamaları}

\author{
Özet \\ Anahtar Kelimeler \\ İkinci virial katsayısi; \\ Sutherland potansiyeli; \\ Termodinamik \\ Sutherland potansiyeli kullanılarak ikinci virial katsayısının hesaplanması için basit ve etkili analitik \\ formül türetildi. İkinci virial katsayısı için Sutherland potansiyeli kullanılarak elde edilen hesaplama \\ sonuçları Lennard-Jones (12-6) ve Exp-6 potansiyelinden elde edilen hesaplama sonuçları ile \\ karşılaştırıldı. Analitik formülün doğruluğu $K r, X e, N e$ ve $A r$ moleküllerine uygulanarak test edildi. \\ Geniş sıcaklık aralığında hesaplama sonuçlarının literatürdeki veriler ile mükemmel bir uyum \\ göstermektedir.
}

(c) Afyon Kocatepe Üniversitesi

\section{Introduction}

The virial coefficients are important in many aspects including the determination of intermolecular interaction with the variation of temperature and the definitions of thermodynamic properties of real gases (heat capacity, Joule-Thomson coefficient, internal energy, sound velocity,...) (Fender and Halsey, 1962; Patria, 1996; McQuarrine and Simon, 1997; Abdulagatov, 2002; Widom, 2002; RamosEstrada et.al., 2004; Kaplan, 2006; Garberoglio et.al., 2011; Meng and Duan, 2012 ). It is common knowledge that the second virial coefficient is widely used in the determination of thermodynamic quantities (Mayer and Mayer, 1948; McQuarrine, 1973; Gibson, 1981). The second virial coefficient is of great interest in many industrial applications (Oh, 2010; Garberoglio et. al., 2012). The second virial coefficient has been determined using intermolecular potentials such as Lennard-Jones (12-6), Exp-6 and Kihara potentials (Hirschfelder et. al., 1954; Vargas et. al., 2001; Mamedov and Somuncu, 2015). Many experimental and theoretical studies have been developed to precisely determine the second virial coefficient of real gases (Vargas et. al., 2001; Glasser , 2002; Vega et. al., 2004; Deszczynski et. al., 2006; Hutem and 
Boonchui, 2012). In spite of many improvements, the accurate evaluation of the second virial coefficient is still one of the main problems in physics and biophysical chemistry (McCarty and Babu, 1970; Garberoglio et. al., 2012; Mohammadi et. al., 2012).

In this study, we proposed a simple and effective analytical formula for the second virial coefficient over Sutherland potential. The obtained results and the implementation of various real gases show a good rate of convergence and numerical stability. Compared to previous analytical methods, our obtained analytical formula is simple and is more appropriate for studying a wide range temperature.

\section{Materials and Methods}

\subsection{Definitions}

The virial equation of state of real gases may be written in the general a series form

$$
\frac{P V}{n R T}=Z=1+B_{2}(\mathrm{~T}) \frac{n}{V}+B_{3}(\mathrm{~T}) \frac{n^{2}}{V^{2}}+\ldots,
$$

which is expansion in powers of the number of molecules per unit volume $n / V$ (Hirschfelder et. al., 1954; McQuarrine and Simon, 1997). The Eq. (1) is called the "virial expansion", and $B_{2}(T), B_{3}(T), \ldots$ are called the second and the third virial coefficient, respectively. These coefficients are depend on temperature and on the potential energy between molecules (Hirschfelder et. al., 1954; McQuarrine, 1973). For an ideal gas $B_{2}(T)=B_{3}(T)=\ldots=0$ (Reif, 1965). The second virial coefficient in terms of intermolecular potential $u(\mathrm{r})$ describes in the as following,

$f\left(r_{i j}\right)=\operatorname{Exp}\left[-\frac{u\left(r_{i j}\right)}{k_{B} T}\right]-1$

$B_{2}(T)=-\frac{1}{2} \int f\left(r_{12}\right) d \tau_{1}$

where $f\left(r_{i j}\right), k_{B}, T$ is Mayer function, the Boltzmann constant, and the temperature, respectively (Kihara, 1953).

\subsection{Expression for the second virial coefficient over Sutherland potential}

To determine the second virial coefficient, we use the Sutherland potential in the following form (Prausinitz et. al., 1999; Kaplan, 2006):

$u(r)= \begin{cases}\infty & r \leq \sigma \\ -\varepsilon\left(\frac{\sigma}{r}\right)^{6} & r>\sigma^{\prime}\end{cases}$

where $\varepsilon$ is the depth of the potential well, $\sigma$ is the finite distance at which the inter-particle potential is zero, and $r$ is the distance between the particles. The second virial coefficient $B_{2}(T)$, in terms of intermolecular potential between particles is defined as (Hutem and Boonchui, 2012)

$B_{2}(T)=-2 \pi N_{A} 10^{-24} \int_{0}^{\infty}\left(e^{-\frac{u\left(r_{12}\right)}{k_{B} T}}-1\right) r_{12}^{2} d r_{12} ，$

where, $N_{A}$ is the Avogadro constant. If the Sutherland potentials substituted into Eq. (5), one gets

$$
\begin{aligned}
B_{2}(T)= & -2 \pi N_{A}\left(\int_{0}^{\sigma}\left(e^{-\left(-\frac{\infty}{k_{B} T}\right)}-1\right) r^{2} d r+\right. \\
& \left.\int_{\sigma}^{\infty}\left(e^{\frac{\varepsilon}{k_{B} T}\left(\frac{\sigma}{r}\right)^{6}}-1\right) r^{2} d r\right)
\end{aligned}
$$

the following series expansion relations is used to integrate as $B_{2}(T)$ analytically (Gradshteyn and Ryzhik, 1965)

$e^{ \pm x}=\sum_{n=0}^{\infty}(-1)^{ \pm n} \frac{x^{n}}{n !}$

which was applied before theoretical studies (Mamedov and Somuncu, 2014; Mamedov and Somuncu, 2015). Then, we obtain the following simply structured formula: 


$$
\begin{array}{r}
B_{2}(T)=\frac{2 \pi N_{A} 10^{-24} \sigma^{3}}{3}\left(e^{\frac{\varepsilon}{k_{B} T}}-\right. \\
\left.\lim _{N \rightarrow \infty} \sum_{n=0}^{N} \frac{1}{n !}\left(\frac{\varepsilon}{k_{B} T}\right)^{n}\left(n+\frac{1}{2}\right)^{-1}\right)
\end{array}
$$

In Eq. (8), the indice $N$ is the upper limit of summations.

\section{Numerical Results}

The parameters $\varepsilon / k_{B} T, \sigma, \gamma$ and $r_{m}$ correspond to diffirent potential are used to describe $K r, \mathrm{Xe}, \mathrm{Ne}$ and $\operatorname{Ar}$ molecules given in Table 1.

Table 1. Potential parameters for some non-polar molecules (Mason and William, 1954; Konowalow and Hirschfelder, 1961; Graben et. al., 1964)

\begin{tabular}{llllllll}
\hline & $\begin{array}{c}\text { Lennard-Jones } \\
(12-6)\end{array}$ & & & Exp-6 & & \multicolumn{2}{c}{$\begin{array}{c}\text { Sutherland } \\
(\infty-6)\end{array}$} \\
\hline Gas & $\sigma$ & $\frac{\varepsilon}{k_{B} T}$ & $\gamma$ & $r_{m}$ & $\frac{\varepsilon}{k_{B} T}$ & (A) & $\frac{\varepsilon}{k_{B} T}$
\end{tabular}

(K)

(K)

(K)

\begin{tabular}{cccccccc}
\hline $\mathrm{Kr}$ & 4.04 & 159 & 12.3 & 4.056 & 158.3 & 3.20 & 491 \\
\hline $\mathrm{Xe}$ & 4.46 & 228 & 13 & 4.450 & 231.2 & 3.62 & 632 \\
\hline $\mathrm{Ne}$ & 3.16 & 36.3 & 14.5 & 3.147 & 38 & 2.4 & 103 \\
\hline $\mathrm{Ar}$ & 3.87 & 119.3 & 14 & 3.866 & 123.2 & 2.95 & 351 \\
\hline
\end{tabular}

The examples of calculations obtained for various values of the parameters are shown in Tables (2-5).

Table 2. Comparative of calculated values of the second virial coefficients of $K r$ for different potentials

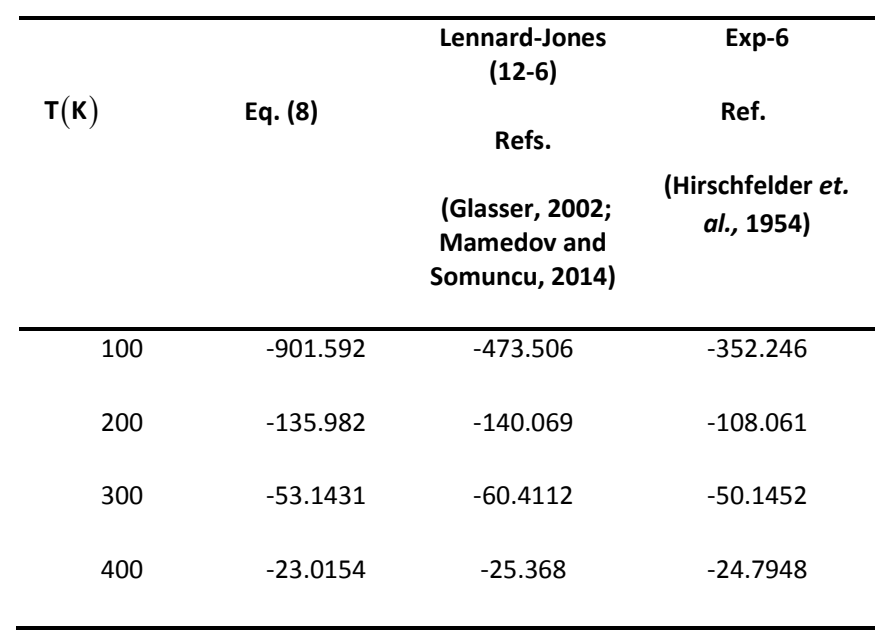

Table 2. Comparative of calculated values of the second virial coefficients of $K r$ for different potentials (Continued)

\begin{tabular}{llll}
\hline 500 & -7.47216 & -5.93586 & -10.804 \\
600 & 2.01426 & 6.26856 & -2.05959 \\
700 & 8.4086 & 14.5563 & 3.84815 \\
800 & 13.0117 & 20.494 & 8.05762 \\
900 & 16.4843 & 24.9171 & 11.1749 \\
1000 & 19.1975 & 28.3105 & 13.5513 \\
1500 & 27.0116 & 37.4339 & 19.8168 \\
2000 & 30.7466 & 41.0746 & 22.1888 \\
2500 & 32.9358 & 42.747 & 23.186 \\
\hline
\end{tabular}

Table 3. Comparative of calculated values of the second

\begin{tabular}{|c|c|c|c|}
\hline $\mathbf{T}(\mathbf{K})$ & Eq. (8) & $\begin{array}{c}\text { Lennard-Jones } \\
(12-6) \\
\text { Refs. } \\
\text { (Glasser, 2002; } \\
\text { Mamedov and } \\
\text { Somuncu, 2014) }\end{array}$ & $\begin{array}{c}\text { Exp-6 } \\
\text { Ref. } \\
\text { (Hirschfelder et. } \\
\text { al., 1954) }\end{array}$ \\
\hline 100 & -3776.51 & -1268.75 & -920.917 \\
\hline 200 & -356.514 & -356.413 & -257.972 \\
\hline 300 & -139.307 & -173.286 & -127.302 \\
\hline 400 & -70.373 & -96.35 & -72.7956 \\
\hline 500 & -36.8798 & -54.416 & -43.2256 \\
\hline 600 & -17.108 & -28.2309 & -24.8314 \\
\hline 700 & -4.05873 & -10.4471 & -12.3825 \\
\hline 800 & 5.20011 & 2.34119 & -3.46094 \\
\hline 900 & 12.1117 & 11.9258 & 3.20277 \\
\hline 1000 & 17.4688 & 19.338 & 8.33808 \\
\hline 1500 & 32.6915 & 39.8439 & 22.4029 \\
\hline 2000 & 39.8628 & 48.6861 & 28.3269 \\
\hline 2500 & 44.0356 & 53.2437 & 31.286 \\
\hline
\end{tabular}
virial coefficients of $X e$ for different potentials

Table 4. Comparative of calculated values of the second virial coefficients of $\mathrm{Ne}$ for different potentials 


\begin{tabular}{|c|c|c|c|}
\hline $\mathbf{T}(\mathbf{K})$ & Eq. (8) & $\begin{array}{c}\text { Lennard- } \\
\text { Jones (12-6) } \\
\text { Refs. } \\
\text { (Glasser, } \\
\text { 2002; } \\
\text { Mamedov } \\
\text { and Somuncu, } \\
\text { 2014) }\end{array}$ & $\begin{array}{c}\text { Exp-6 } \\
\text { Ref. } \\
\text { (Hirschfelder } \\
\text { et. al., 1954) }\end{array}$ \\
\hline 100 & -252.395 & -251.85 & -177.505 \\
\hline 200 & -49.3811 & -69.6099 & -48.8305 \\
\hline 300 & -15.0598 & -22.3355 & -15.9376 \\
\hline 400 & -1.05016 & -1.15357 & -1.31103 \\
\hline 500 & 6.56388 & 10.627 & 6.77125 \\
\hline 600 & 11.3499 & 17.9993 & 11.7964 \\
\hline 700 & 14.6375 & 22.9693 & 15.1607 \\
\hline 800 & 17.0355 & 26.4952 & 17.5294 \\
\hline 900 & 18.8621 & 29.0907 & 19.2584 \\
\hline 1000 & 20.2999 & 31.0549 & 20.5546 \\
\hline 1500 & 24.4931 & 36.101 & 23.7808 \\
\hline 2000 & 26.525 & 37.8649 & 24.7939 \\
\hline 2500 & 27.7243 & 38.4938 & 25.0589 \\
\hline
\end{tabular}

Table 5. Comparative of calculated values of the second virial coefficients of $\mathrm{Ar}$ for different potential

\begin{tabular}{|c|c|c|c|}
\hline $\mathbf{T}(\mathbf{K})$ & Eq. (8) & $\begin{array}{c}\text { Lennard-Jones } \\
(12-6) \\
\text { Refs. } \\
\text { (Glasser, 2002; } \\
\text { Mamedov and } \\
\text { Somuncu, 2014) }\end{array}$ & $\begin{array}{c}\text { Exp-6 } \\
\text { Ref. } \\
\text { (Hirschfelder } \text { et. } \\
\text { al., 1954) }\end{array}$ \\
\hline 100 & -4.3687 & -8.02982 & -5.24466 \\
\hline 200 & 7.57936 & 11.4683 & 8.00672 \\
\hline 300 & 11.0543 & 16.773 & 11.5301 \\
\hline 400 & 12.7112 & 18.9669 & 12.9424 \\
\hline 500 & 13.6812 & 20.0318 & 13.5957 \\
\hline
\end{tabular}

Table 5. Comparative of calculated values of the second virial coefficients of $A r$ for different potential (Continued)

\begin{tabular}{llll}
\hline 600 & 14.3182 & 20.5818 & 13.9068 \\
700 & 14.7685 & 20.8639 & 14.0422 \\
800 & 15.1037 & 20.9944 & 14.0798 \\
900 & 15.363 & 21.034 & 14.0602 \\
1000 & 15.5695 & 21.017 & 14.0057 \\
1500 & 16.1842 & 20.5865 & 13.5391 \\
2000 & 16.4888 & 20.0241 & 13.0263 \\
2500 & 16.6708 & 19.4893 & 12.5585 \\
\hline
\end{tabular}

The results of calculated from the Eq. (8) and literature for the second virial coefficient with Lennard-Jones (12-6) and Exp-6 potentials are plotted in Figures (1-4).

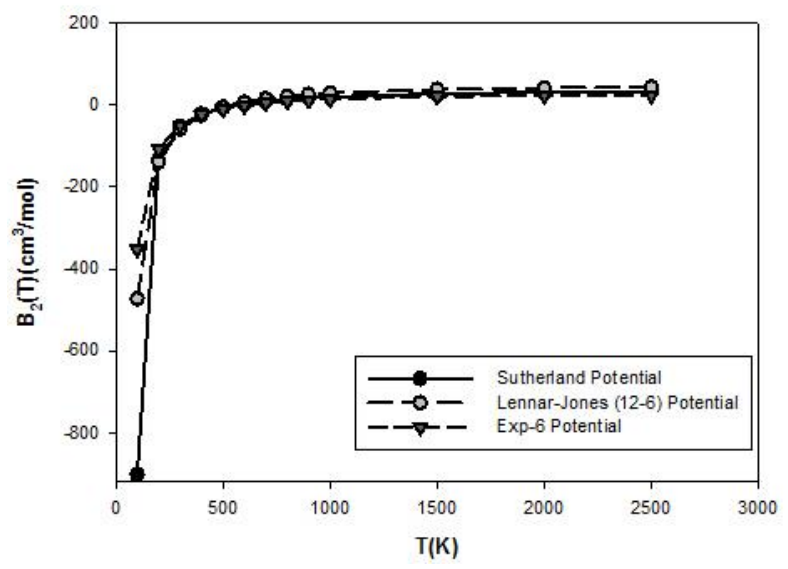

Figure 1. The second virial coefficient of $K r$ plotted against temperature

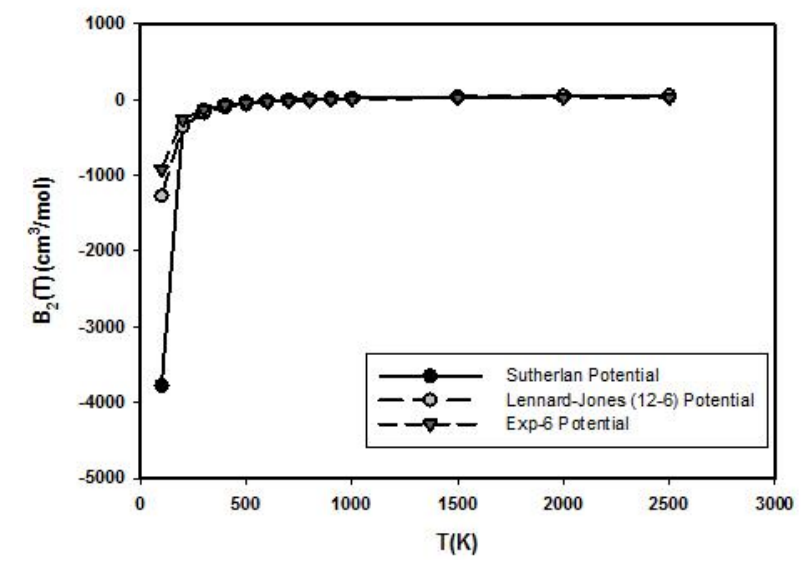

Figure 2. The second virial coefficient of Xe plotted against temperature 


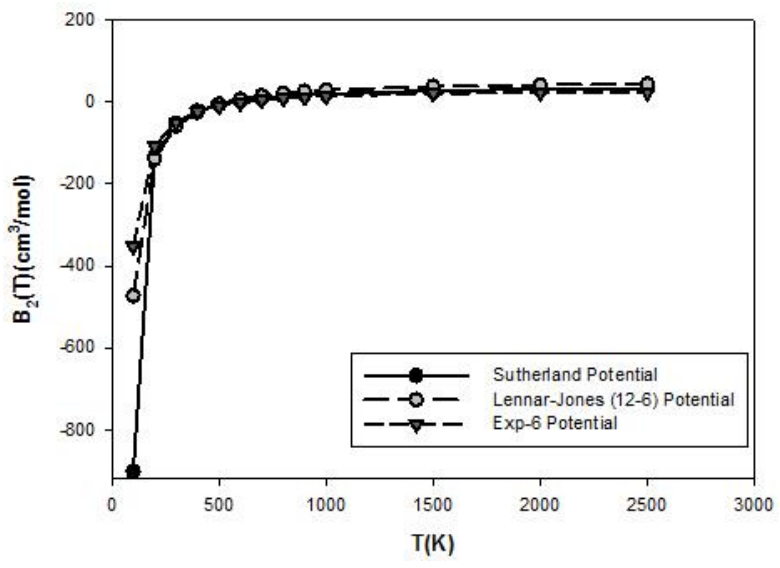

Figure 3. The second virial coefficient of $\mathrm{Ne}$ plotted against temperature

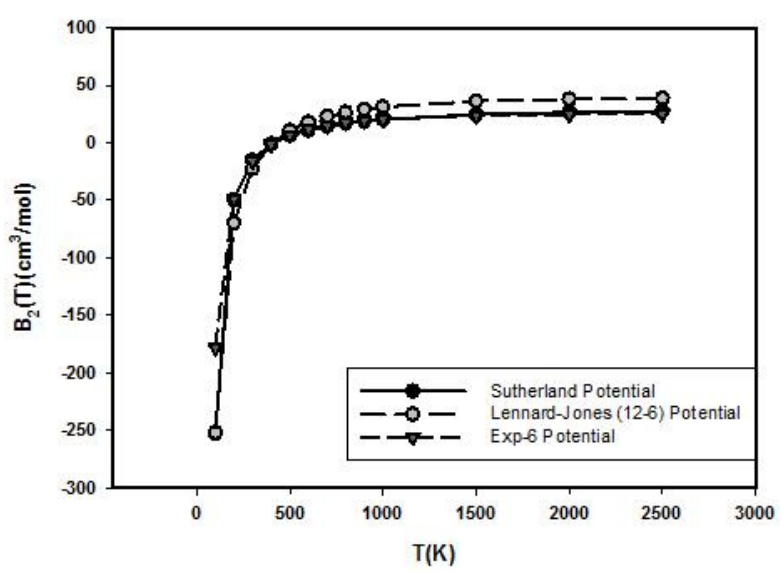

Figure 4. The second virial coefficient of $A r$ plotted against temperature

\section{Discussion and Conclusion}

In this paper, a simple approximate analytical expression for second virial coefficient derived using Sutherland potential. The obtained formula is completely general and can be used to calculate some of the thermodynamic properties of real gases for the arbitrary values temperature. Note that this expression gives very accurate results for a wide range of temperature. This should prove their usefulness not only for checking the accuracy of numerical values of the second virial coefficient computed by other types of approximations but also as a practical computational tool in applications. The Mathematica 7.0 international mathematical software was used to calculate the analytical expression obtained in this paper.

The results obtained for $B_{2}(T)$ are showed an excellent agreement with the literature data (Hirschfelder et. al., 1954; Hostettler and Bernstein, 1959; Graben et. al., 1964; Levi and Llano, 1975; Mi, et. al., 2008; Mamedov and Somuncu, 2014; Mamedov and Somuncu, 2015). Tables (2-5) show the calculated results of the second virial coefficients for molecules $K r, \mathrm{Xe}, \mathrm{Ne}$ and $\mathrm{Ar}$.

The results obtained from the Eq. (8) and literature for second virial coefficient over Lennard-Jones (126) (Glasser, 2002; Mamedov and Somuncu, 2014) and Exp-6 potentials (Hirschfelder et. al., 1954) are plotted in Figures (1-4). Notice that in Figures (1-4), although the intermolecular potentials have different, the gases do so with nearly the same slopes. It is understood from the compatibility of the graphics that the results are in good agreement with literature data (Hirschfelder et. al., 1954; Hostettler and Bernstein, 1959; Graben et. al., 1964; Levi and Llano, 1975; Vargas, et. al., 2001; Glasser, 2002; Mi, et. al., 2008; Hutem and Boonchui, 2012; Mamedov and Somuncu, 2014; Mamedov and Somuncu, 2015).

The Lennard-Jones (12-6), Exp-6 and Sutherland potentials include the theoretically sound $r^{-6}$ longrange interaction. Sutherland potential can be useful for investigating simple and complex molecules and it is a special case of the LennardJones potential with infinitely steep repulsion. As can be seen Tables (2-5) and Figures (1-4), second virial coefficient takes positive values at high temperature and negative values at low temperature. The positive values indicate that two molecules repulsive each other. The negative values indicate that two molecules attract each other in the low velocity collisions. The attraction is what reasons molecules to condense at sufficiently low temperatures. Over a wide temperature range, the analytical formula offers the advantage of direct and precise calculation of second virial coefficient. 


\section{ACKOWLEDGEMENTS}

This work has been supported by the Scientific and Technological council of Turkey (TUBITAK) Science Fellowships and Grant Programmes Department (BIDEB).

\section{References}

Abdulagatov, A. I., Kaplun, A. B., Meshalkin, A. B., Abdulagatov, I. M. and Stepanov, G. V., 2002. Second Caloric Virial Coefficients for Real Gases and Combined Spherical Symmetric Potential for Simple Molecular Interactions. Journal of Chemical Thermodynamics, 34, 2049-2072.

Deszczynski, M., Harding, S. E., Winzor, D. J., 2006. Negative Second Virial Coefficients as Predictors of Protein Crystal Growth: Evidence From Sedimentation Equilibrium Studies that Refutes the Designation of Those Light Scattering Parameters as Osmotic Virial Coefficients. Biophysical Chemistry, 120, 106 113.

Fender, B. E. F. and HalseyJr, G. D., 1962. Second Virial Coefficients of Argon. Krypton. and ArgonKrypton Mixtures at Low Temperatures. Journal of Chemical Physics, 36, 1881.

Garberoglio, G., Moldever, M. R. and Harvey, A. H., 2011. Improved First-Principles Calculation of the Third Virial Coefficient of Helium. Journal of Research NIST, 116, 729-742.

Garberoglio, G., Jankowski, P., Szalewicz, K., and Harvey, A. H., 2012. Second Virial Coefficents of $\mathrm{H}_{2}$ and its isotopologues from a six-dimensional potential. Journal of Chemical Physics, 137, 154308- 154319.

Gibson, W. G., 1981. Third Virial Coefficient for Quantum Hard Spheres: Two-Point Padé Appraximants for Direct and Exchange Parts. Journal of Statistical Physics, 26, 333-346.

Glasser, M. L., 2002. Second virial coefficient for a Lennard-Jones $(2 n-n)$ system in d dimensions and confined to a nanotube surface. Physics Letters $A, 300,381-384$.

Graben, H. W., Present, R. D., 1964. Third Virial Coefficient for the Sutherland $(\infty, v)$ Potential. Reviews of Modern Physics., 1025-1033.

Gradshteyn, I. S., Ryzhik, I. M., 1965. Exponential Integrals. Tables of Integrals. Series and Products. Acedemic, London. 1-1762.

Hirschfelder, J.O., Curtiss, C. F., Bird, R. B., 1954. Molecular Theory of Gases and Liquids. USA Jonh Wiley \& Sons. 1-931.
Hostettler, H. U., Bernstein, R. B., 1959. Comparison of Exp-6, L-J (12.6) and Sutherland Potential Functions Applied to the Calculation of Differential Scattering Cross Sections. Journal of Chemical Physics, 31, 1422-1423.

Hutem, A. and Boonchui, S., 2012. Numerical Evaluation of Second and Third Virial Coefficients of Some Inert Gases via Classical Cluster Expansion. Journal of Mathematical Chemistry, 50, 1262-1276.

Kaplan, I. G., 2006. Intermolecular Interactions: Physical Picture, Computational Methods and Model Potentials. Jonh Wiley \& Sons, 183-200.

Kihara, T., 1953. Virial Coefficiens and Models of Molecules in Gases. Review of Modern Physics, 25, 831-843.

Konowalow, D. D. and Hirschfelder, J. O., 1961. Intermolecular Potential Functions for Nonpolar Molecules. Physics of Fluids, 4, 629-635.

Levi, D., M. Llano, D., 1975. Closed Form of Second Virial Coefficient for Sutherland Potential. Journal of Chemical Physics, 63, 4561-4562.

Mamedov, B. A. and Somuncu, E., 2014. Analytical Treatment of Second Virial Coefficient over Lennard-Jones (2n-n) Potential and its Application to Molecular Systems. Jounal of Molecular Structure, 1068, 164-169.

Mamedov, B. A. and Somuncu, E., 2015. Accurate Calculation of Second Virial Coefficient of the Exp-6 Potential and Its Application. Physica A, 420, 246-257.

Mason, E. A. and William, E. R., 1954. The Intermolecular Potentials of Helium and Hydrogen. Journal of Chemical Physics, 22, 522535.

Mayer, E. J. and Mayer, M. G., 1948. Statistical Mechanics. John Wiley \&Son, New York, 277294.

McQuarrie D. A., 1973. Statistical Mechanics. Harper \& Row, New York, 222-245.

McCarty, M., Babu, .S.V.K., 1970.First Quantum Corrections to Second Virial Coeffiicent of Stockmayer Gas. Journal of Physical Chemistry, 74, 1113-1115.

McQuarrie, D. A. and Simon, J. D., 1997. Physical Chemistry: A Molecular Approach. University Science Books Sausalito Calfornia, 49-82.

Meng, L. and Duan, Y. Y., 2006. Site-Site potential function and second virial coefficients for linear molecules. Molecular Physics, 104, 2891-2899.

Mi, J., Tang, Y., Zhong, C., 2008. Theoretical Study of Sutherland Fluids with Long-Range, Short-Range, and highly Short-Range Potential Parameters. 
Journal of Chemical Physics, 128, 054503054510.

Mohammadi, A., Saadatabadi, A. R., Khanpour, M., 2012. Second Virial Coeffiecients of Exp-6 Chains: A Monte Carlo Simulation. Chemical Physics, 397, 26-33.

Oh, S. K., 2010. Extending the Group Contribution Concept Using Kihara Potential to Perfluorinated n-alkanes $C_{n} F_{2 n+2}(n=1-6)$ for Estimating Thermophysical. Fluid Phase Equilibria, 288, 87-95.

Pathria, R. K., 1996. Statistical Mechanics. Second Edition, Elsevier Press, 299-340.

Prausnitz, J. M., Lichtenthaler, R. N., Azevedo, E. G. de, 1999. Fugacities in Gas Mixtures.Molecular Thermodynamics of Fluid Phase Equilibria. Prentice-Hall, New Jersey, 123-211.

Ramos-Estrada, M., Tellez-Morales, R., IglesiasSilva, G. A., Hall, K. R., 2004. A generalized correlation for the second virial coefficient based upon the Stockmayer potential. Latin American Applied Research, 34, 34-41.

Reif, F., 1965. Fundementals of Statistical Mechenics and Thermal Physics. McGraw-Hill, New York.1333.

Vargas, P., Munoz, E., Rodriguez, L., 2001. Second Virial Coefficient for the Lennard-Jones Potential. Physica A, 290, 92-100.

Vega, C., McBridge, C., Menduina, C., 2002. The Second Virial Coefficient of the DipolarTwo Center Lennard-Jones Model. Physical Chemistry Chemical Physics, 4, 3000-3007.

Widom, B., 2002. Statistical Mechanics: A Concise Introduction for Chemists. Cambridge Universty Press.1-1322. 